\title{
Winter's Charm', Winter's Hope', and Winter's Star' Camellias
}

\author{
W.L. Ackerman ${ }^{1}$ and D.R. Egolf ${ }^{2}$ \\ U.S. Department of Agriculture, U.S. National Arboretum, \\ Washington, DC 20002
}

\begin{abstract}
Additional index words. Camellia oleifera, C. sasanqua, C. hiemalis, ornamentals, breeding
\end{abstract}

Camellias in the mid-Atlantic region of the United States have been devastated by winter severity during the past 15 years. Devastation in the region is similar to that experienced at the U.S. National Arboretum (USDA zone 7b, U.S. Dept. of Agriculture, 1990) which, in 1976, possessed a collection of $>900$ camellia specimens $(750$ Camellia japonica L., 120 C. sasanqua Thunb. ex. J.A. Murray, and lesser numbers of other species), many 25 to 35 years old. Camellia oleifera Abel (PI 162475) was uninjured, and fewer than a dozen other specimens [four $C$. japonica, three $C$. sasanqua, and four $C$. sinensis (L) Kuntz], although severely injured, survived -17C during Winter 197879. This same winter, plants of $C$. oleifera (PI 162561) were uninjured at -21C at Ashton, Md. (USDA zone 6b). An on-going breeding program toward greater cold hardiness was expanded in 1979.

Camellia sasanqua and C. hiemalis Makai, two fall-blooming species, have served as excellent landscape plants in southern gardens. Their showy autumnal floral displays, ranging from white to pink, magenta, and red, appear in the Maryland area from October to mid-December. These plants should be considered too susceptible to winter injury to be grown much further north than USDA zone 8a without risk of damage (Ackerman, 1978)

Plants of $C$. oleifera grown north as far as Maryland and southern Pennsylvania (USDA zone 6b) have shown no winter injury. These observations led us to use proven hardy strains of C. oleifera (PI 162475 and PI 162561) in interspecific crosses with selected $C$. sasanqua, C. hiemalis, and C. vernalis cultivars. Although the flowers of $C$. oleifera have little ornamental value, the plants have attractive foliage and considerable ornamental 'grace. The breeding objective was to combine the desirable floral qualities of selected $C$. sasanqua and $C$. hiemalis cultivars with plant characteristics and hardiness of $C$. oleifera.

Received for publication 26 July 1991. Accepted for publication 9 Dec. 1991. The cost of publishing this paper was defrayed in part by the payment of page charges. Under postal regulations, this paper therefore must be hereby marked advertisement solely to indicate this fact.

${ }^{1}$ Research Horticulturist (retired)

${ }^{2}$ Research Horticulturist (deceased).

\section{Origin}

In 1969, interspecific crosses were made using C. oleifera (PI 162561) during a species compatibility study (Ackerman, 1971) that resulted in two $\mathrm{F}_{1}$ hybrid releases, 'Frost Prince' and 'Frost Princess' (Ackerman, 1981). From 1979 to 1981 , two C. oleifera introductions (PI 162475 and PI 162561) were used to produce $\mathrm{F}$, and backcross hybrids.

'Winter's Charm' and 'Winter's Star' originated from $F_{1}$ interspecific crosses, while 'Winter's Hope' was developed from a backcross to $C$. oleifera. These crosses were conducted at the U.S. Plant Introduction Station,

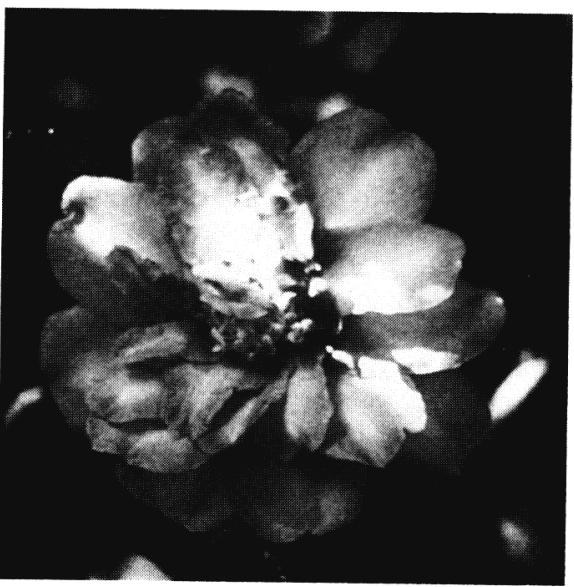

Fig. 1. 'Winter's Charm' C. sasanqua ‘Takuraawase' $\times$ C. oleifera.

Glenn Dale, Md., and are in addition to three recently introduced hybrids named 'Winter's Rose,' 'Snow Flurry,' and 'Polar Ice' (Ackerman and Egolf, 1991) and differ from the latter in flower and/or plant form.

\section{Description}

Winter's Charm' (NA 62301, PI 547259). Camellia sasanqua 'Takura-awase' $\times \mathrm{C}$.

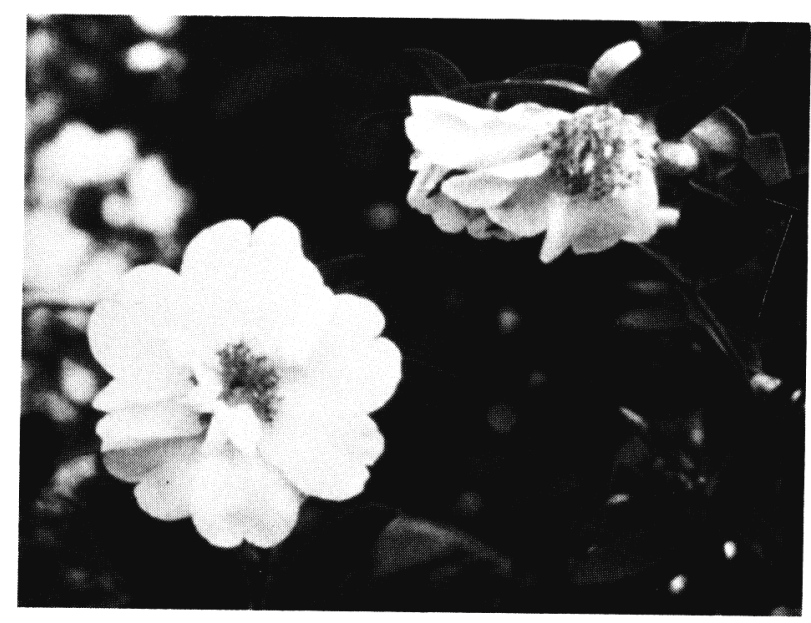

Fig. 2. 'Winter's Hope' $C$. oleifera $\times$ 'Frost Princess' $(C$. hiemalis $\times C$. oleifera).

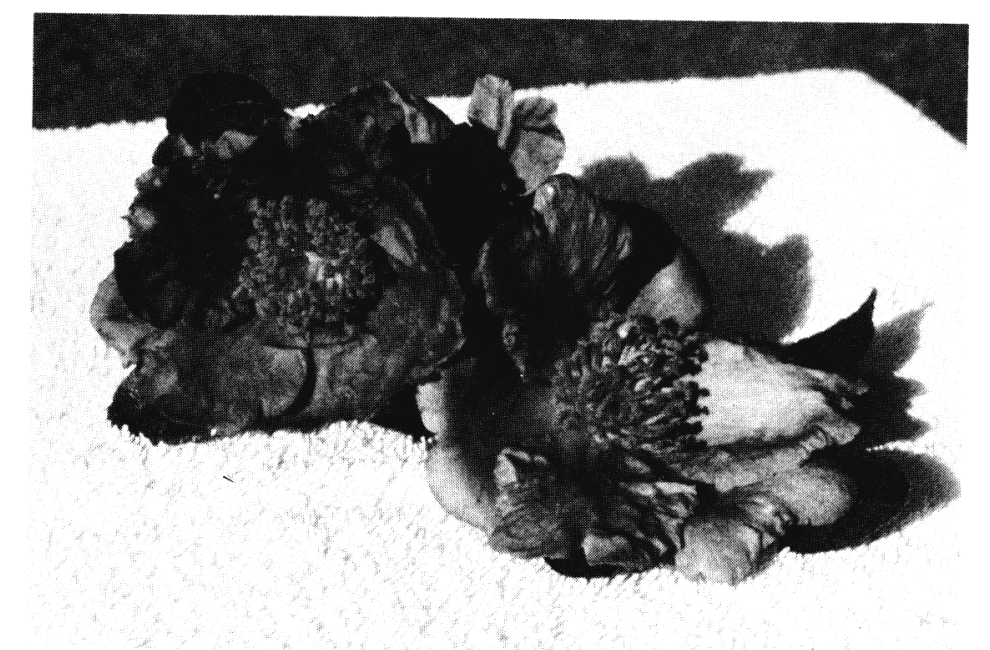

Fig. 3. 'Winter's Star' C. oleifera $\times$ C. hiemalis 'Showa-no-Sakae' 
oleifera (PI 162561) survived winters outdoors at Ashton (USDA zone 6b) and experienced no damage during 7 years, despite temperatures as low as $-23 \mathrm{C}$, without protection other than a canopy provided by large Pinus virginiana trees. The shrub has grown to $1.9 \mathrm{~m}$ high and $1.3 \mathrm{~m}$ wide in 10 years. Leaves are leathery, glossy dark green, obovate, $9 \mathrm{~cm}$ long, $4 \mathrm{~cm}$ wide, with coarsely serrated margins. Flowers are $9 \mathrm{~cm}$ in diameter, lavender pink (Purple 75B) (Royal Horticultural Soc., 1982), peony form, with 14 petals, and 14 petaloids. It blooms from October through November, frequently up to 6 weeks in Maryland. At senescence, flower petals fall separately.

'Winter's Hope' (NA 62302, PI 547260). Camellia oleifera (PI 162475) $\times$ 'Frost Princess' [C. hiemalis $\times C$. oleifera (PI 162561)] survived winters outdoors at London Town Publik House and Gardens, Edgewater, Md. (USDA zone 7a). No damage occurred during 9 years, despite temperatures as low as $-21 \mathrm{C}$ without protection other than a canopy provided by large pine and hardwood trees. The shrub has grown $2.4 \mathrm{~m}$ high and $2.3 \mathrm{~m}$ wide in 12 years. Leaves are leathery, glossy, very dark green, ovate, $8 \mathrm{~cm}$ long, $4.5 \mathrm{~cm}$ wide, with crenate margins. Flowers are $9.5 \mathrm{~cm}$ in diameter, white, semi-double, with 12 petals. It blooms from October through November, frequently up to 5 weeks in Maryland. At senescence, flower petals fall separately.

'Winter's Star' (NA 62303, PI 547261). Camellia oleifera (PI 162475) $\times$ C. hiemalis 'Showa-no-Sakae' survived winters outdoors at Glenn Dale (USDA zone 6b) and showed no damage during 9 years, despite temperatures as low as $-24 \mathrm{C}$, without protection other than an open frame structure covered with $40 \%$ black plastic shadecloth. The shrub has grown $2.1 \mathrm{~m}$ high and $1.6 \mathrm{~m}$ wide in 12 years. Leaves are leathery, semi-glossy, medium green, obovate, $9.5 \mathrm{~cm}$ long, $4 \mathrm{~cm}$ wide, with crenate to somewhat serrate margins. Flowers are $8.5 \mathrm{~cm}$ in diameter, redpurple (Red-Purple $74 \mathrm{C}$-D), single, with six petals. It blooms from October through November, frequently up to 6 weeks in Maryland. At senescence, flower petals fall separately.

All three cultivars have been free of diseases and insects. The most serious camellia diseases are flower petal blight, dieback, and root rot. Dieback is rare in the northern areas where these cultivars are recommended, and petal blight does not normally attack fallblooming species. The most serious camellia insects are the scale insects. No assurances can be given that these hybrid cultivars are more resistant to scale than other camellias.

\section{Availability}

Plants produced under U.S. National Arboretum stock increase have been distributed to cooperating wholesale nurseries. Limited quantities of cuttings or scions are available to plant breeders and nurseries by writing to the U.S. National Arboretum, 3501 New York Ave., NE, Washington, DC 20002.

\section{Literature Cited}

Ackerman, W.L. 1971. Genetic and cytological studies with camellia and related species. U.S. Dept. Agr. Tech. Bul. 1427.

Ackerman, W.L. 1978. The Camellia sasanqua dilemma-are $C$. oleifera hybrids the answer? p. 117-121. In: M.H. Brown (ed.). American camellia yearbook. R.L. Bryan, Columbia, S.C.

Ackerman, W.L. 1981. 'Frost Prince' and 'Frost Princess' Camellias. HortScience 16(5):690.

Ackerman, W.L. and D. Egolf. 1991. 'Winter's Rose,' 'Snow Flurry,' and 'Polar Ice' Camellias. HortScience 26(11):1432-1433.

U.S. Department of Agriculture. 1990. Plant hardiness zone map. Misc. Publ. 1475, Agr. Res. Serv.

Royal Horticultural Society. 1982. Royal Horticultural Society Colour Chart. London. 